\title{
PREVALENCE OF OVERWEIGHT \& OBESITY IN ADULT URBAN WOMEN
}

Pradeep P. Shinde, Anant Pawar,

1. Assistant Professor, Department of Community Medicine, KMCT Medical Collage. Calicut, Kerala.

2. Associate Professor, Department of Community Medicine, KMCT Medical Collage. Calicut, Kerala.

\section{CORRESPONDING AUTHOR}

Pradeep. P. Shinde.

KMCT Medical College,

Mannasary, Calicut, Kerala.

E-mail: pradip_14819@rediffmail.com

Ph: 00919822714819

ABSTRACT: BACKGROUND: Prevalence of obesity is increasing in all Indian population. Obesity is a major risk factor for many non-communicable diseases. AIM \& OBJECTIVE: To study the prevalence of overweight and obesity in adult females. To study various epidemiological factors associated with overweight \& obesity. METHODS: A community based cross sectional study was conducted and 635 women were studied. Predesigned questionnaire was used to collect relevant socio-demographic information. Anthropometric measurements such as weight, height, waist circumference and hip circumference were measured using standard techniques. RESULTS: In study population prevalence of overweight was $17.17 \%$ and obesity was $6.45 \%$; while $38.26 \%$ had central obesity. Obesity was significantly associated with age, socio-economic status and physical activity. CONCLUSIONS: Prevalence of obesity is increasing in India. This observation emphasizes large scale awareness campaign about obesity. KEYWORDS: Overweight, Obesity, women

INTRODUCTION: Obesity is an increasingly important public health problem of global significance ${ }^{1}$. Diet, eating pattern, physical inactivity, sedentary lifestyles, environmental factors, alcohol consumption, improved health facilities, increase in income and availability of food and psychological factors contribute to obesity 2,3 . This global epidemic is related to increased mortality and morbidity rates with excess body fat being a significant risk factor for a non chronic disorders such as CVD, NIDDM, gout, gall stones, intestinal blockage, kidney disease, sleep apnea, hernia and arthritis, it also increases likelihood of backache and flat foot ${ }^{3,4}$. In addition, the obese suffer from bias, prejudice and discrimination. As obesity is a life threatening problem, giving rise to various complications, ways and means of reducing the occurrence of obesity need to be explored. According to the National Family Health Survey-3 (NFHS-3) in India, overweight and obesity are three times higher in urban areas than in rural areas and are more common among women ${ }^{5}$.

\section{AIM \& OBJECTIVES:}

- To study the prevalence of overweight and obesity in adult females.

- To study various epidemiological factors associated with overweight \& obesity.

MATERIAL \& METHODS: A community based cross sectional study was conducted in the field practice area of urban health center run by community medicine department of medical college. A house to house survey was done and all females above 20 years of age were included in study. Females with disorder such as any pathological oedema, cushing's syndrome and pregnancy 
were excluded from study. A total of 635 subjects were included in study. Detailed information regarding age, sex, educational status, marital status, occupation and occupational activity, religion, etc. was obtained using predesigned questionnaire. Modified B.G. Prasad classification updated for June 2011 was used for socioeconomic classification. Anthropometric measurements such as weight, height, waist circumference and hip circumference were measured using standard techniques. BMI was calculated using formula weight/ height in $\mathrm{m}^{2}$ and Waist hip ratio was calculated by dividing waist circumference by hip circumference. Waist hip ratio was used for defining the central obesity. In female, WHR $>0.85$ indicates central obesity. Data was then analysed for results.

RESULTS:A total of 635 women above 20 years of age were studied, out of these $109(17.17 \%)$ were overweight while 41 (6.45\%) had obesity; overall prevalence of overweight and obesity in present study was $23.62 \%$ (table-1). On the other hand in present study $243(38.26 \%)$ had central obesity i.e. waist-hip ratio above 0.85 .

In present study increase in prevalence of overweight and obese with increase in age was observed. Women in age group of 40 to 49 had highest $40.49 \%$ prevalence of obesity. This association between age and obesity was statistically significant. Similarly significant association was observed between age and central obesity (table- 2).

In present study we could establish statistically significant association of obesity with socio-economic status. Prevalence of obesity increased as socio-economic status improved (table 3). Physical inactivity was important cause of obesity in our study. Women with sedentary lifestyle had highest $50.53 \%$ prevalence of overweight and obesity. This association between physical inactivity and obesity was also statistically significant (table-4)

DISCUSSION: In this study population, the prevalence of overweight (BMI > 25) was $17.17 \%$ and the prevalence of obesity (BMI $>30$ ) was $6.45 \%$. This was higher than the prevalence of obesity $15.6 \%$ estimated by Misra et al $^{6}$ in females in an urban slum population in North India. The prevalence of overweight/obesity was highest (39.18\%) in the age group between 40-49 years and there was significant association between the prevalence of overweight/obesity and age. In line with our study Misra et al ${ }^{6}$ had reported significant increasing trend in the prevalence of obesity with advancing age.

Another significant observation of this study was the association of socio-economic status with the risk of being overweight and obese. Socioeconomic status is a factor which has been linked to problem of overweight and obesity by many other authors $7,8,9$.

In present study women with sedentary lifestyle had highest $50.53 \%$ prevalence of overweight and obese. This association between physical inactivity and obesity was also statistically significant. A large multi-centric study conducted in five cities of India has shown highly significant association between sedentary lifestyle and obesity ${ }^{10}$.

CONCLUSIONS AND RECOMMENDATIONS: The prevalence of obesity is increasing in urban women of India. Improving socio-economic status and sedentary lifestyle along with advancing age are major risk factors for development of obesity. Obesity is associated with very severe long term health hazards such as diabetes mellitus, dislipidemia, polycystic ovarian disease, hypertension etc. The epidemic of obesity needs to be controlled at earliest. A large scale awareness campaign to sensitize population regarding long term complications of obesity and measures to prevent obesity needs to be launched. 


\section{REFERENCES:}

1. World Health Organization. Obesity: preventing and managing the global epidemic. Technical Report Series No. 894, Geneva: WHO 2000: 559-690.

2. Goel K, Misra A, Vikram NK, Poddar P, Gupta N (2010). Subcutaneous abdominal adipose tissue is associated with the metabolic syndrome in Asian Indians independent of intraabdominal and total body fat. Heart 2010: 96: 579-583.

3. Misra A, Khurana L, Vikram NK, Goel A, Wasir JS. Metabolic syndrome in children: current issues and South Asian perspective. Nutrition. 2007; 23: 895-910.

4. Hill JO, Peters JC et al (1998). Environmental contributions to the obesity epidemic. Science 2008: 1371-1374.

5. National Family Health Survey-3, India, 2005-2006 Adult Nutrition: (cited 2009 May 10) availableonwww.nfhsindia.org/NFHS.../NFHS3\%20

Nutritional\%20Status\%20of\%20Adults.ppt.

6. Misra A, Pandey RM, Devi JR, Sharma R, Vikram NK, Khanna N. A high prevalence of diabetes, obesity and dyslipidaemia in an urban slum population in northern India. Int J Obes Relat Metab Disord 2001; 25:1722-29

7. Kaur S, Sachdev HP, Dwivedi SN, Lakshmy R, Kapil U. Prevalence of overweight and obesity amongst school children in Delhi, India. Asia Pac J Clin Nutr 2008; 17: 592-596.

8. Gupta R, Goyle A, Kashyap S, Agarwal M, Consul R. Prevalence of atherosclerosis risk factors in adolescent school children. Indian Heart J 1998;50: 511-515.

9. Mohan V, Shanthirani S, Deepa R, Premalatha G, Sastry NG, Saroja R et al. Chennai Urban Population Study (CUPS No. 4). Intra-urban differences in the prevalence of the metabolic syndrome in southern India - the Chennai Urban Population Study (CUPS No. 4). Diabet Med 2001; 18:280-87.

10. Singh RB, Pella D. Prevalence of obesity, physical inactivity and undernutrition, a triple burden of diseases during transition in a developing economy. The Five City Study Group. Acta Cardiol 2007; 62:119-27.

Table No. 1 Distribution of study subjects according to BMI

\begin{tabular}{|l|l|l|}
\hline BMI & No. of women in group & Percentage \\
\hline$<18.5$ & 121 & 19.05 \\
\hline $18.5-24.99$ & 364 & 57.32 \\
\hline $25-29.99$ & 109 & 17.17 \\
\hline $30-34.99$ & 29 & 4.57 \\
\hline $35-39.99$ & 11 & 1.73 \\
\hline$>40$ & 1 & 0.16 \\
\hline Total & 635 & 100 \\
\hline
\end{tabular}


Table No. 2 Relationship between age and obesity

\begin{tabular}{|l|l|l|l|l|l|}
\hline Age group & $\begin{array}{l}\text { Total No. Of } \\
\text { subjects in } \\
\text { group }\end{array}$ & $\begin{array}{l}\text { Overweight } \\
\text { and obese }\end{array}$ & $\begin{array}{l}\text { Prevalence in } \\
\text { percentage }\end{array}$ & $\begin{array}{l}\text { Subjects with } \\
\text { WHR >0.8 }\end{array}$ & $\begin{array}{l}\text { Prevalence in } \\
\text { percentage }\end{array}$ \\
\hline $20-29$ & 224 & 27 & 12.05 & 31 & 13.83 \\
\hline $30-39$ & 171 & 44 & 25.73 & 79 & 46.19 \\
\hline $40-49$ & 148 & 58 & 39.18 & 93 & 62.83 \\
\hline $50-59$ & 57 & 16 & 28.07 & 28 & 49.12 \\
\hline$>60$ & 35 & 5 & 14.28 & 12 & 34.28 \\
\hline & 635 & 150 & 23.62 & 243 & 38.26 \\
\hline
\end{tabular}

$\mathrm{X}^{2}$ for obesity $=39.17, \mathrm{df}=4, \mathrm{p}<0.001$

$\mathrm{X}^{2}$ for $\mathrm{WHR}=102, \mathrm{df}=4, \mathrm{p}<0.0001$

Table No. 3 Relationship between SES and obesity

\begin{tabular}{|l|l|l|l|l|}
\hline Social class & $\begin{array}{l}\text { Total No. Of } \\
\text { subjects in class }\end{array}$ & $\begin{array}{l}\text { Overweight and } \\
\text { obese }\end{array}$ & Non-obese & $\begin{array}{l}\text { Prevalence of } \\
\text { obesity }\end{array}$ \\
\hline I & 24 & 2 & 22 & 8.33 \\
\hline II & 76 & 7 & 69 & 9.21 \\
\hline III & 140 & 19 & 121 & 13.57 \\
\hline IV & 377 & 119 & 258 & 31.56 \\
\hline V & 18 & 3 & 15 & 16.66 \\
\hline Total & 635 & 150 & 485 & 23.62 \\
\hline $\begin{array}{l}\mathrm{X}^{2}=31.21, \mathrm{df}=2, \mathrm{p}<0.001 \\
\text { For calculation social class I clubbed with social class II and social class IV with V }\end{array}$ \\
\hline
\end{tabular}

Table No. 4 Relationship between physical activity and obesity

\begin{tabular}{|l|l|l|l|l|}
\hline Physical activity & $\begin{array}{l}\text { Total No. Of } \\
\text { subjects in group }\end{array}$ & $\begin{array}{l}\text { Overweight and } \\
\text { obese }\end{array}$ & Nonobese & $\begin{array}{l}\text { Prevalence in } \\
\text { group }\end{array}$ \\
\hline Sedentary & 186 & 94 & 92 & 50.53 \\
\hline Light & 377 & 46 & 331 & 12.20 \\
\hline Moderate & 45 & 6 & 39 & 13.33 \\
\hline Heavy & 27 & 4 & 23 & 14.81 \\
\hline Total & 635 & 150 & 485 & 23.62 \\
\hline $\begin{array}{l}\mathrm{X}^{2}=105.69, \mathrm{df}=2, \mathrm{p}<0.0001 \\
\text { For calculation sedentary activity moderate and heavy clubbed together }\end{array}$ \\
\hline
\end{tabular}

